NBER WORKING PAPER SERIES

\title{
TARIFFS IN AN ECONOMY WITH INCOMPLETE MARKETS AND UNEMPLOYMENT
}

Raquel Fernandez

Working Paper No. 2705

NATIONAL BUREAU OF ECONOMIC RESEARCH

1050 Massachusetts Avenue

Cambridge, MA 02138

September 1988

I wish to thank R. Braid, A. Dixit, M. Obstfeld, and especially R. Feenstra for their helpful comments and suggestions on an earlier version of this paper which was presented at the VI Annual Latin American Reunion of the Econometric Society. This research is part of NBER's research program in International Studies. Any opinions expressed are those of the author not those of the National Bureau of Economic Research. 
NBER Working Paper \#2705

September 1988

\title{
TARIFFS IN AN ECONOMY WITH INCOMPLETE MARKETS AND UNEMPLOYMENT
}

\begin{abstract}
This paper examines the optimal labor contract in a small open economy with incomplete markets under international price uncertainty. The effect on employment, wages, and profits of different realizations of the state of nature is studied and agents' preferences concerning the implementation of a tariff are determined. The implicit contract equilibrium is shown to be constrained Pareto optimal; unanticipated tariff policy cannot be Pareto improving over free trade.
\end{abstract}

\author{
Raquel Fernandez \\ Department of Economics \\ Boston University \\ 270 Bay State University \\ Boston, MA 02215
}




\section{TARIFFS IN AN ECONOMY WITH INCOMPLETE MARKETS AND UNEMPLOYMENT}

\section{Introduction}

The threat of unemployment is one of the most popular arguments in favor of protectionism. Although international trade economists have dedicated much attention to examining the consequences of protectionist measures in various situations, they have done so far less for economies in which unemployment exists. This relative absence of analysis reflects, in large part, the difficulty inherent in the introduction of unemployment into economic models in a manner both tractable and consistent with microeconomic foundations. The literature that does analyze the interrelations between international trade and unemployment, does so in economies in which the latter results from the existence of rigid or slowly adjusting wages (e.g. Johnson (1965), Lapan (1976), and Neary (1982)) or from the presence of minimum wages (Brecher (1974)) $)^{1}$.

This paper seeks to analyze the implications of a tariff in an economic environment in which the existence of incomplete markets under uncertainty leads agents to recur to the factor market, via implicit contracts, as a way of providing partial insurance against income instability. As demonstrated by the implicit contracts literature, unemployment is then a possibility in some states of nature.

1. A significant exception is Matusz (1985, 1986). 
As a theory of unemployment implicit contract theory, of course, has its shortcomings. As Akerlof and Miyazaki (1980) show, unemployment results only when the marginal revenue product of labor, evaluated at full employment, is less than the reservation utility of a worker. More sophisticated models, however, that allow for asymmetry in information, risk aversion on the part of the firm, and require contracts to be incentive compatible are able to generate unemployment under conditions in which the above inequality is reversed (e.g. Grossman and Hart (1983), Azariadis (1983)). Overall, the main contribution of implicit contract theory - the perception of employment and wage-setting as a long term relation that involves risk sharing - seems a valuable one whose consequences deserve to be explored.

Although trade under uncertainty has itself been the subject of several recent studies, these have primarily focused on the relevance of the basic theorems of international trade either in the absence of any risk sharing mechanisms or under the assumption that solely international risk sharing through international trade in equities is possible. Thus Newbery and Stiglitz (1984) demonstrate, by means of an example, the possibility of Pareto inferior trade in an economy in which risk sharing is inexistent and Helpman and Razin (1978) establish the standard results of the Heckscher-Ohlin-Samuelson model in a stock market model in which international trade in equities is permitted.

With the notable exceptions of Ethier $(1982,1985)$ and Matusz (1985, 1986), however, the possibility of agents providing insurance by entering into implicit contracts has been ignored by trade 
theorists. Ethier uses the basic result of the simplest contract model - state invariant wages - as a framework in which to explain dumping and the employment of migrant labor. Matusz examines the validity of the fundamental theorems of the Heckscher-Ohlin-Samuelson model with implicit contracts and the welfare and employment effects of trade in a Ricardian model with implicit contracts.

Matusz's analysis assumes (as does all the implicit contract literature to my knowledge) that there is no aggregate uncertainty in the economy. Uncertainty results from iid technological shocks to individual firms that enter the production function in a multiplicative fashion. Consequently all aggregate variables are nonstochastic. International trade is not in itself a cause of unemployment but may, by changing relative prices, influence its size. In contrast, the analysis undertaken here assumes that uncertainty is a product of fluctuations in the terms of trade and hence is aggregate and a consequence of the openness of the economy. Furthermore, in contrast with the standard partial equilibrium treatment of implicit labor contracts, the level of agents' expected utility and expected profits is endogenously determined. 2

Several questions are suggested by this approach. It is of interest to examine how the implicit contract determines factor prices and employment as a function of the terms of trade. This leads to an understanding of how income is divided among agents in "good" versus "bad" times. A next step is to ask how a tariff, imposed after the

${ }^{2} \mathrm{An}$ exception is Horn and Svensson (1986) who use a general equilibrium model of implicit contracts to analyze optimal labor contracts in the presence of trade unions. 
international terms of trade are known, affects the distribution of income and the level of employment within the economy. An important question is whether tariffs may constitute a Pareto improvement over free trade. That is, to the extent that import relief legislation manifests a social desire to provide insurance, is a tariff an efficient instrument for doing so? ${ }^{3}$

Independently of any threat of unemployment, an important argument for protection is that commercial policy is able to play a role in providing ins rance when domestic markets are incomplete. (This argument is especially important in the context of developing economies where market incompleteness is thought to be more prevalent.) Eaton and Grossman (1985) show, for example, that in a sector-specific economy with no risk sharing mechanisms a marginal tariff at free trade may increase social welfare. The question then arises, however, whether a tariff may constitute a Pareto improvement over free trade in an environment in which some form of domestic insurance - in this case implicit contracts - exists.

\section{The Model}

Consider a small open economy that produces two goods ( $\mathrm{X}_{1}$ and $\mathrm{X}_{2}$ ) with one factor of production, labor (L). Technology in each sector, F and $G$, is assumed to be quasi-concave, twice differentiable, with $F(0)=G(0)=0$ and $F^{\prime}(0)=G^{\prime}(0)=\infty$. To simplify notation assume that there is only one firm in each sector. The economy is populated by two types

${ }^{3}$ For example, article XIX of the GATT and section 201 of the U.S. Trade Act of 1974 allow tariff concessions (reductions) to be withdrawn if a product is imported in such quantities so as to cause serious injury to domestic producers. 
of agents characterized by their objectives, endownents, and attitudes towards risk: entrepreneurs own firms and maximize expected profits and $\ell$ risk-averse workers own their labor and maximize expected utility. ${ }^{4}$ Reflecting the assumption that firms make some sort of firm specific investment in their workers, labor is assumed to be ex ante mobile and ex post immobile, i.e. once employed in a firm labor is, for at least the short to medium-run time interval considered here, firm specific. Workers possess identical utility functions and identical indivisible endowments of labor.

As a result of, for example, an uncertain degree of import competition for good $x_{1}$, the economy faces uncertainty in the terms of trade. So that, letting $X_{2}$ be the numeraire of the economy and $P$ be the relative price of $x_{1}$ in terms of $X_{2}, P$ is a random variable that fluctuates between $\underline{P} \leq P \leq \bar{P}$. As has been shown by the implicit contracts literature, given the above risk preference assumptions it is mutually advantageous under uncertainty for entrepreneurs and workers to formulate a "contract" specifying the employment level of and the income to be paid to workers in each state of nature (where each realization of $P, P$, is associated with a different state of nature). 5 This enables workers to trade-off some of the income instability which they are subject to as a consequence of a fluctuating marginal revenue product in a full employment, perfectly competitive environment and

4. Entrepreneurs are assumed to be endowed with a sufficient quantity of good $\mathrm{X}_{2}$ so as to prevent bankruptcy in any state of nature.

5. The clasic references are Azariadis (1975), Baily (1974), and Gordon (1974). The implicit contracts literature has been reviewed recently by Rosen (1985) and Hart and Holmstrom (1986). 
permits the risk-neutral entrepreneur to lower the expected wage bill. Hence, assuming that entrepreneurs and workers know the probability distribution $h(p)$ of $P$, both parties will enter into an implicit contract.

Prior to the realization of the state of nature the firm decides the quantity of workers, $N$, with which it wishes to contract given the market level of expected utility: $\tilde{U}$, that each contracted worker must receive. Those workers are then offered a contract of the form $c_{i}=\left(e_{i p}, w_{i p}\right)$ where $i=1,2$ denotes the sector to which the firm belongs, $e_{i p}$ is the probability of a contracted worker being employed in state $p$, and $w_{i p}$ is the wage offered in that state. Workers either work, contributing their total endowment of labor, and enjoy indirect utility $V(w, p)$, or are unemployed with utility $\hat{U}$. The latter can be interpreted as the utility derived from the leisure available when unemployed or from a state-invariant non-tradable consumption basket of goods obtained by home production during unemployment. I assume, as in Azariadis (1975), that firms cannot offer workers unemployment insurance. ${ }^{6}$ Furthermore, contracts are assumed to be incentive compatible so that entrepreneurs are restricted to wages such that $\mathrm{V}(.) \geq \hat{\mathrm{U}}$ ip. 7

6 . This assumption ensures that we are in a second best world. Large transactions costs or some form of moral hazard is needed to justify it.

7. It is assumed throughout the analysis that this constraint is not binding. 
Consider the maximization problem faced by the firm in the sector that produces the imported good, $x_{1} \cdot 8$ The firm's objective is to maximize expected profit subject to an expected utility constraint and an employment constraint. Thus, the firm solves:

$$
\begin{aligned}
w_{w}, e^{\operatorname{Max}}, \int_{P} & \left.\int_{\underline{P}}^{-}(p F(L)-w L)\right) d H \\
\text { s.t. } & \int_{l \geq e, \forall p}^{P}(V(w, p) e+\hat{U}(1-e)) d H \geq \bar{U}
\end{aligned}
$$

where $H(p)=\int_{p}^{p} h(p) d p, N_{1}$ is the number of workers contracted with in sector one, and $\mathrm{L}=\mathrm{Ne}$ is the number of workers actually employed in state $\mathrm{p} \cdot{ }^{9}$

The first constraint ensures that workers receive expected utility equal to the competitive level. The utility of a worker conditional on state $\mathrm{p}$ is the sum of the utility obtained when employed, weighted by the probability of employment, and the utility derived when unemployed, weighted by the probability of unemployment. The second continum of constraints guarantee that the firm does not hire more workers, in any state of nature, than the total labor pool with which it contracted.

The first order conditions (foc) with respect to $w$, e, and $\mathrm{N}_{1}$ derived from (1) are:

8. It is assumed that for the given range of $P, X_{1}$ is always imported and $\mathrm{x}_{2}$ exported. Furthermore, it is implicitly assumed that entrepreneurs consume only the numeraire good.

9. For notational convenience subscripts $i$ and $p$ are omitted wherever their presence is not required for clarity. 


$$
\begin{aligned}
& \text { (i). } V_{w}-N / \lambda \\
& \text { (ii). } \mathrm{PF}_{L} \mathrm{~N}-\mathrm{wN}+\lambda(\mathrm{V}-\hat{\mathrm{U}})-\gamma_{\mathrm{P}}=0 \\
& \text { (iii). } \int_{?}^{\bar{p}}\left\{\left(\mathrm{PF}_{L}-\mathrm{w}\right) \mathrm{e}\right\} \mathrm{dH}=0
\end{aligned}
$$

and the Kuhn-Tucker conditions:

$$
\gamma_{\mathrm{p}} \geq 0, \quad 1-\mathrm{e} \geq 0, \gamma_{\mathrm{p}}(1-\mathrm{e})=0
$$

where $\lambda$ is the Lagrange multiplier associated with the first constraint and $\gamma_{p}$ the Lagrange multiplier associated with the second constraint in state p.)

The first foc determines optimal risk sharing between workers and entrepreneurs and requires the marginal utility of the wage to be constant over all states of nature. The second requires the cost of a marginal reduction in the probability of employment, $\quad P F_{L} N+\lambda(V-\hat{U})$, to exceed or equal the benefit, wN. The first term, $\mathrm{pF}_{\mathrm{L}} \mathrm{N}$, measures the value of the loss in output resulting from a marginal decrease in e. The term $\lambda(V-\hat{U})$ is the amount by which the wage bill would have to be increased in order to restore workers to the same level of utility as prior to the decrease in the probability of employment, i.e. $\mathrm{Nedw} /\left.\mathrm{de}\right|_{U}$ where $\mathrm{U}(\mathrm{p})=\mathrm{Ve}+\hat{\mathrm{U}}(1-\mathrm{e})$. Note that $\mathrm{dw} /\left.\mathrm{de}\right|_{\mathrm{U}}$ is multiplied by Ne reflecting the fact that all employed workers must receive the increased wage. An implication of (2-ii) is that when the solution is interior (i.e. when there is unemployment), the wage is greater than the value of the marginal product of labor. A reversal of this inequality is feasible only in the corner solution (i.e. at full employment) . 
The third foc determines the optimal quantity of workers that the firm should contract. It requires the expected benefit from a marginal increase in the quantity of contracted workers

$$
\int P F_{L} e d H \text {, to equal the expected cost, } \int \text { wedH. e appears in }
$$

both terms since a contracted worker is not necessarily an employed worker and hence the probability of employment is the relevant variable in calculating expected cost and benefit.

The maximization problem of the firm in the export sector is identical to ( 1 ) with $p$ replaced by 1 and $F$ by $G$. The first order conditions follow as in (2) with the corresponding modifications.

Equilibrium is attained in the economy at $U^{*}$ when all workers receive a contract from one of the two sectors of the economy so that $\tilde{U}_{i}=U^{*}>\hat{U} \forall i$ and $\Sigma N_{i}=\ell, i=1,2$, or the utility from a contract is $\hat{U}$ and $\Sigma N_{i} \leq l$. (Ex ante mobility of workers ensures that the expected utility of contracting with either sector is equal in equilibrium.) Existence and uniqueness of equilibrium follows from (i) a perfectly inelastic supply curve of labor for $\tilde{U} \geq \hat{U}$ and (ii) a downward sloping demand curve for labor. Appendix I proves that the number of workers that a firm wishes to contract with is a negative function of $\tilde{U}$.

Equilibrium in the labor market is depicted in Figure 1 . It is assumed throughout the analysis that the equilibrium attained is such that $U^{*}>\hat{U}$ and hence that all workers receive a contract. 


\section{Characterization of the Contracts}

This section analyzes the income distributional and welfare consequences of different states of nature. That is, it examines the effect on wages, profits, and on different agents' welfare of states of nature in which the terms of trade are relatively higher or lower. Note that this analysis differs from that obtained by asking how the contract itself would change if the distribution of prices had, for example, a higher mean or a lower variance; we are inquiring about movements along a given contract. While of interest in its own right, this will also prove helpful when examining the question of whether a tariff may constitute a Pareto improvement over free trade.

Note that the constancy of the marginal utility of the wage required by $(2-i)$ cannot be interpreted as implying a state-invariant wage rate since changes in the relative price of $x_{1}$ affect the marginal utility of income. Use of the implicit function rule on (2-i) yields:

$$
d w / d p=-V_{w p} / V_{w w}
$$

It is assumed that $\mathrm{v}_{\mathrm{ww}}<0$. The sign of $\mathrm{V}_{\mathrm{wp}}$ is derived by differentiating Roy's identity

$$
\mathrm{v}_{\mathrm{p}}=-\mathrm{CV} \mathrm{w}
$$

with respect to $w$ (where $C$ is the amount of good $X_{1}$ consumed by an employed worker). This yields, after a few manipulations:

$$
\mathrm{V}_{\mathrm{wp}}=\mathrm{V}_{\mathrm{w}} \mathrm{C}\left(\mathrm{R}^{*}-\Phi\right) / \mathrm{w}
$$

where $R^{*}-\left(V_{w w} \cdot w\right) / V_{w}$ is the coefficient of relative risk aversion and $\Phi-(\partial C / \partial w) \cdot(w / C)$ is the income elasticity of demand for $X_{1}$. Therefore,

$$
\mathrm{dw} / \mathrm{dp}=\mathrm{C}\left(\mathrm{R}^{*}-\Phi\right) / \mathrm{R}^{*}
$$


Thus the sign of (7) depends on the relative magnitudes of $R^{*}$ and $\Phi$. (If, for example, homothetic preferences are assumed, $d w / d p \geq 0$ as $R^{*} \geq 1$

Assuming that the distribution of the terms of trade is such that full employment obtains for some states of nature and unemployment for others, the import sector will be at full employment at the higher realizations of $P$ and the export sector at the lower realizations. In neither sector is the transition from full employment to unemployment discontinuous; as p changes gradually, the level of employment does not jump downwards when unemployment obtains. Since all functions in (2-ii) are continuous in $p$, a downward jump of employment (implying an upward jump in $F_{L}$ ) would require an upward jump in $\gamma_{p}$ and hence $\gamma_{p}>0$ which is incompatible with the Kuhn-Tucker condition for unemployment.

The effect of a marginal increase in $p$ on employment in the import sector when unemployment exists is derived by differentiating (2-ii) with respect to $p$ and using Roy's identity, yielding:

$$
\mathrm{dL}_{1} / \mathrm{dp}=-\left(\mathrm{F}_{\mathrm{L}}-\mathrm{C}_{1}\right) / \mathrm{p} \mathrm{F}_{\mathrm{LL}}
$$

the sign of which depends on the magnitude of consumption of good $\mathrm{x}_{1}$ by an employed worker in sector one relative to the marginal product of labor in that sector. Throughout the analysis it shall be assumed that

$$
\mathrm{F}_{\mathrm{L}}>\mathrm{C}_{1}
$$

so that employment is an increasing function of the terms of trade.

The ambiguity in (8) can be understood in the following fashion. (2-ii) states that when unemployment exists, the cost to the firm of a marginal decrease in the probability of employment should equal the marginal benefit. A marginal increase in $p$ increases this cost by $F_{L}$ 
thus creating an incentive to increase e and hence employment in that state of nature. It also, however, increases the marginal berefit of lowering e by $C_{1}$ since the increased price of good $x_{1}$ implies that employment in that state of nature is less attractive and hence that the firm's wage compensation to workers for a lower employment probability is smaller, i.e. dw/dp/U C. If the increase in marginal benefit is greater than the increase in marginal cost, the firm should decrease the quantity of labor hired, thus obtaining the "counterintuitive" result that employment is, for some range of the terms of trade, a decreasing function of $p$.

In the export sector, differentiation of (2-ii) yields:

$$
\mathrm{dL}_{2} / \mathrm{dp}=\mathrm{C}_{2} / \mathrm{G}_{\mathrm{LL}}
$$

so that employment is a decreasing function of $\mathrm{p}$.

The behavior of employment in both sectors as a function of the terms of trade is shown in Figure 2.

The effect of a marginal price increase on profits in sector one depends on the status of employment in that sector. Differentiating the profit function with respect to p and using (7) obtains:

$$
\mathrm{d} \pi_{1} / \mathrm{dp}=\left(\mathrm{pF}_{\mathrm{L}}-\mathrm{w}_{1}\right) \mathrm{dL} \mathrm{L}_{1} / \mathrm{d} \mathrm{p}+\mathrm{F}-\mathrm{C}_{1} \mathrm{~L}_{1}+\Phi_{1} \mathrm{C}_{1} \mathrm{~L}_{1} / \mathrm{R}_{1} *
$$

Noting that (9) implies that $F>C_{1} L_{1}$, it follows that when in the range of prices in which sector one has full employment a marginal increase in $p$ causes sector one profits to increase. When the economy has unemployment, $d L_{1} / d p>0$, so that a marginal increase in $p$ has an ambiguous effect on profits.

In the export sector (sector 2), differentiation of the profit function with respect to $\mathrm{p}$ yields:

$$
\mathrm{d} \pi_{2} / \mathrm{dp}=\left(\mathrm{G}_{\mathrm{L}}-\mathrm{w}_{2}\right) \mathrm{dL}_{2} / \mathrm{dp}-\mathrm{C}_{2} \mathrm{~L}_{2}+\Phi_{2} \mathrm{C}_{2} \mathrm{~L}_{2} / \mathrm{R}_{2} \text { * }
$$


indicating that under full employment profits move in the opposite direction to the wage and that with unemployment profits may increase or decrease with the terms of trade.

The effect of slightly higher realizations of $P$ on the conditional utility of workers in sector one, $U_{1}(p)$,

$$
\mathrm{U}_{1}(\mathrm{p})=\mathrm{V}\left(\mathrm{w}_{1}, \mathrm{p}\right) \mathrm{e}+\hat{\mathrm{U}}(1-\mathrm{e})
$$

likewise depends on whether the sector is at full employment. Differentiating (13) and using (7) yields

$$
\mathrm{dU}_{1} / \mathrm{dp}=-\left(\mathrm{V}_{\mathrm{w}} \Phi_{1} \mathrm{C}_{1} \mathrm{e}_{1}\right) / \mathrm{R}_{1}{ }^{*}+\left[(\mathrm{V}-\hat{\mathrm{U}}) / \mathrm{N}_{1}\right] \cdot \mathrm{dL}_{1} / \mathrm{dp}
$$

so that under full employment workers' conditional utility is a decreasing function of $p$. Equation (14) makes it clear that, although it is not possible to sign (7), the effect on $V(w, p)$ of a higher [lower] realization of $P$ and the associated wage change warranted by the contract is negative [positive]. This is a consequence of the optimal risk sharing condition which requires the marginal utility of income to be constant over states of nature.

With unemployment the sign of (14) is ambiguous since it depends on whether the net negative effect of a price increase-wage change on utility outweighs the positive effect on utility of an increase in the probability of employment. Although (11) and (14) cannot be unambiguously signed when unemployment exists, multiplication of (11) by $V_{w} / N$ and recalling from $(2-i i)$ that $p F_{L}-w=-(V-\hat{U}) / V_{w}$ yields:

$$
\left(\mathrm{V}_{\mathrm{w}} / \mathrm{N}_{1}\right) \cdot \mathrm{d} \pi_{1} / \mathrm{dp}=-\mathrm{dU} \mathrm{U}_{1} / \mathrm{dp}+\left(\mathrm{F}-\mathrm{C}_{1} \mathrm{~L}_{1}\right) \mathrm{V}_{\mathrm{w}} / \mathrm{N}_{1}
$$

indicating that, given a price increase, profits necessarily increase if workers' utility falls and that workers' utility increases if profits fall. Therefore, it is impossible for a price increase to simultaneously make both parties to the contract worse off. Alternatively, a price decrease cannot make both parties better ff 
Setting expression (14) equal to zero it is possible to solve for the income transfer $\left(d_{1}\right)$ that sector one workers would require in order to be just as well off as prior to the price change.

$$
\mathrm{L}_{1} \mathrm{dv}_{1}=\left\{\left(\Phi_{1} \mathrm{C}_{1} \mathrm{~L}_{1}\right) / \mathrm{R}_{1}{ }^{*}-\left[(\mathrm{V}-\hat{\mathrm{U}}) / \mathrm{V}_{\mathrm{w}}\right] \cdot \mathrm{dL}_{1} / \mathrm{dp}\right\} \mathrm{dp}
$$

where (14) has previously been multiplied by $\mathrm{N}_{1}$ to include the effect of the price change on the conditional utility of all workers in sector one. Note, however, that $d_{1}$ is multiplied by $L_{1}$ respecting the restriction that only employed workers may receive income transfers.

Setting (11) equal to zero yields the transfer $\left(d z_{1}\right)$ required by entrepreneurs in sector one to keep profits constant

$$
\mathrm{d} z_{1}=-\left\{\left(p F_{L}-w\right) d L_{1} / d p+F-C_{1} L_{1}+\Phi_{1} C_{1} L_{1} / R_{1}^{*}\right\} d p
$$

Hence,

$$
\mathrm{L}_{1} \mathrm{dv} \mathrm{v}_{1} / \mathrm{dp}+\mathrm{d} z_{1} / \mathrm{d} \mathrm{p}_{1}=-\left(\mathrm{F}-\mathrm{C}_{1} \mathrm{~L}_{1}\right)<0
$$

Thus, if compensation is allowed, agents in sector one would prefer a higher to a lower price for good $x_{1}$.

The conditional utility of workers in sector two, however, unambiguously decreases with a price increase regardless of the status of employment

$$
\mathrm{dU}_{2} / \mathrm{dp}=-\left(\mathrm{V}_{\mathrm{w}} \Phi_{2} \mathrm{C}_{2} \mathrm{e}_{2}\right) / \mathrm{R}_{2}{ }^{*}+\left[(\mathrm{V}-\hat{\mathrm{U}}) / \mathrm{N}_{2}\right] \cdot \mathrm{dL}_{2} / \mathrm{dp}
$$

since, unlike the case for sector one workers, the probability of employment is a decreasing function of $p$.

Performing the same compensation exercise as for sector one agents yields:

$$
\left.L_{2} d v_{2} *\left\{\Phi_{2} C_{2} L_{2}\right) / R_{2}^{*}+\left[(V-\hat{U}) / V_{w}\right] \cdot d L_{2} / d p\right\} d p
$$

and

$$
d z_{2}=-\left\{\left(G_{L}-w_{2}\right) d L_{2} / d p-C_{2} L_{2}+\Phi_{2} C_{2} L_{2} / R_{2}{ }^{*}\right\}
$$

Hence, 


$$
\mathrm{L}_{2} \mathrm{dv_{2 }} / \mathrm{dp}+\mathrm{d} z_{2} / \mathrm{dp}=\mathrm{C}_{2} \mathrm{~L}_{2}>0
$$

so that, if compensation is allowed, agents in sector two would prefer

a lower to a higher price for $\mathrm{x}_{1}$.

The results derived in this section differ from those of Jones (1971) sector-specific model or the Heckscher-Ohlin-Samuelson model.

Under full employment in both sectors the economy behaves more along the lines predicted by the Stolper-Samuelson theorem. A price increase pits all workers against sector one entrepreneurs; the position of sector two entrepreneurs is ambiguous. When there is unemployment in a least one sector of the economy, however, various combinations of agents gaining and losing are possible including outcomes with the flavor of the sector-specific model in which all agents in sector one favor the price increase and those in sector two are opposed.

\section{Welfare Analysis of a Tariff}

This section analyzes the question of whether a tariff can constitute a Pareto improvement over free trade. The tariff examined is imposed by the government after the state of nature is known but before firms have made their decision as to the particular identity of the workers to be hired or laid off. This reflects the assumption that the government is unable to make state contingent transfers, otherwise the economy could simply proceed to the first best by allowing the government to play any viable insurance role.

The tariff is unanticipated. This case is of interest because the government cannot make state contingent plans and, moreover, ex ante policies would tend to be time inconsistent. Thus the scenario is one in which the government knows the unemployment that will result (if 
any) under the particular state of nature that has been realized, and may choose to impose a tariff.

The imposition of a tariff implies that firms and workers alter the original wage-employment decision to that determined by the contract for the state of nature corresponding to the tariff inclusive price. That is, it is as if the contract had been written with the states of nature given by the domestic price level $p^{*} \mathrm{p}^{*}(1+t)$, where $\mathrm{p}^{*}$ denotes the free trade relative price of good $x_{1}$, so that a tariff, as far as the contract is concerned, merely moves the economy to a state of nature corresponding to higher realizations of $\mathrm{p}^{*}$.

The possibility of a tariff improving welfare appears more likely when the economy has unemployment in sector one and full employment in sector two since in this situation a small tariff unambiguously increases employment and the value of output at free trade prices.

To analyze whether in this situation a tariff is capable of permitting a Pareto improvement over free trade, we examine the set of constrained Pareto optima described by the solutions to

$$
\begin{aligned}
& \operatorname{Max} E=V\left(w_{1}+s_{1} / L_{1}, p^{\star}(1+t)\right) L_{1}+\hat{U}\left(N_{1}-L_{1}\right)+ \\
& \mu_{1}\left(\mathrm{~V}\left(\mathrm{w}_{2}+\mathrm{s}_{2} / \mathrm{N}_{2}, \mathrm{p}^{*}(1+\mathrm{t})\right)\right\} \mathrm{N}_{2}+\mu_{2}\left\{\mathrm{G}-\mathrm{w}_{2} \mathrm{~N}_{2}+\mathrm{s}_{3}\right\}+ \\
& \mu_{3}\left[\mathrm{P}^{*}(1+t) \mathrm{F}-\mathrm{w}_{1} \mathrm{~L}_{1}-\mathrm{s}_{1}-\mathrm{s}_{2}-\mathrm{s}_{3}+\mathrm{T}\right]
\end{aligned}
$$

for values of $\mu_{i} \geq 0, i=1,2,3$. Different choices for the values of $\mu_{i}$ correspond to different points on the utility-possibility frontier. $\mathrm{N}_{2}=\ell-\mathrm{N}_{1}, s_{i}$ is a lump sum transfer of income to employed workers in sector $i, i=1,2$ or to entrepreneurs in sector two, $i=3$, and $T$ is the tariff revenue.

Note that the formulation of (23) assumes that the government is able to engage in lump-sum transfers of income among employed workers 
and entrepreneurs but not to unemployed workers. This respects the initial restriction faced by entrepreneurs prohibiting them from providing unemployed workers with insurance. Insofar as the government is forced to respect the same restrictions as entrepreneurs, this avoids one of critiques of this literature in that the government's conduct of trade policy is not ad hoc assumed to be free of the constraints faced by the private market. 10

The foc for this problem are:

$\partial f / \partial s_{1}=\mathrm{V}_{\mathrm{yl}}+\mu_{3}\left[-1+\mathrm{dT} / \mathrm{ds} s_{1}\right]=0$

$\partial f / \partial s_{2}=\mu_{1} V_{y_{2}}+\mu_{3}\left[-1+d T / d s_{2}\right]=0$

$\partial f / \partial s_{3}=\mu_{2}+\mu_{3}\left[-1+d T / d s_{3}\right]=0$

$\partial f / \partial t=v_{y 1}\left[d w_{1} / d t-C_{1} p^{*}-s_{1} /\left(L_{1}\right)^{2} \cdot d_{1} / d t\right] L_{1}+\left(v_{1}-\eta\right) d L_{1} / d t+$

$$
\mu_{1} V_{y 2}\left[d w_{2} / d t-C_{2} p^{*}\right]+\mu_{2}\left[N_{2} d w_{2} / d t\right]+
$$

$\mu_{3}\left[\left(\mathrm{pF}_{\mathrm{L}}-\mathrm{w}_{1}\right) \mathrm{dL} \mathrm{L}_{1} / \mathrm{d} t+\mathrm{p}^{*} \mathrm{~F}-\mathrm{L}_{1} \mathrm{dw_{1 }} / \mathrm{d} t+\mathrm{dT} / \mathrm{dt}\right]=0$

Differentiation of $T=t p^{*}\left(C_{1} L_{1}+C_{2} N_{2}-F\right)$ yields:

$$
\partial \mathrm{T} / \partial s_{i}=t p^{*} \partial C_{i} / \partial y_{i} i=1,2 \text { and } \partial T / \partial s_{3}=0
$$

It can easily be shown that the free trade equilibrium $\left(t=s_{i}=0\right)$ fulfills the necessary conditions for a constrained Pareto optimum. Noting that $\partial \mathrm{T} /\left.\partial s_{i}\right|_{t=0^{-0}}$ yields:

$$
\mathrm{V}_{\mathrm{yl}}=\mu_{1} \mathrm{~V}_{\mathrm{y} 2}-\mu_{2}=\mu_{3}
$$

Hence, using Roy's identity obtains:

$\partial f /\left.\partial t\right|_{t=s i=0}=V_{y l}\left(-p^{*} I+d T /\left.d t\right|_{t=s i=0}+\left(\mathrm{pF}_{L^{-}} w_{1}\right) d L_{1} / d t+\right.$

$$
\left.\left[\left(\mathrm{v}_{1}-\eta\right) / \mathrm{V}_{\mathrm{yl}}\right] \mathrm{dL} \mathrm{L}_{1} / \mathrm{dt}\right\}
$$

${ }^{10}$ See Dixit (1986) for this and related criticism of trade policy in the context of incomplete markets. 
where $I$ is the quantity imported of $X_{1}$. Differentiation of $T$ with respect to the tariff rate yields:

$$
\begin{gathered}
\mathrm{dT} /\left.\mathrm{dt}\right|_{\mathrm{si}=0}=\left\{\mathrm{p}^{*} \mathrm{I}+\mathrm{tp}{ }^{*}\left(\left[\partial \mathrm{C}_{1} / \partial \mathrm{y}_{1} \cdot\left(\mathrm{dw_{1 }} / \mathrm{dt}\right)+\left(\partial \mathrm{C}_{1} / \partial \mathrm{p}\right) \cdot \mathrm{p}^{*}\right] \mathrm{L}_{1}+\right.\right. \\
\left.\left.\left[\partial \mathrm{C}_{2} / \partial \mathrm{y}_{2} \cdot\left(\partial \mathrm{w}_{2} / \partial \mathrm{t}\right)+\left(\partial \mathrm{C}_{2} / \partial \mathrm{p}\right) \mathrm{p}^{*}\right] \mathrm{N}_{2}-\left(\mathrm{F}_{\mathrm{L}}-\mathrm{C}_{1}\right) \mathrm{dL} \mathrm{L}_{1} / \mathrm{dt}\right\}\right\}
\end{gathered}
$$

Hence,

$$
\mathrm{dT} /\left.\mathrm{dt}\right|_{\mathrm{t}=0}=\mathrm{p}^{*} \mathrm{I}
$$

Consequently,

$$
\mathrm{df} /\left.\mathrm{dt}\right|_{t=0}=\left\{\mathrm{V}_{\mathrm{yl}}\left\{\left(\mathrm{p} \mathrm{F}_{\mathrm{L}}-\mathrm{w}_{1}\right)+\left(\mathrm{V}_{1}-\hat{\mathrm{U}}\right) / \mathrm{v}_{\mathrm{y} 1}\right\} \mathrm{dL} \mathrm{L}_{1} / \mathrm{dt}\right.
$$

Noti $g$ that $\left.y_{1}\right|_{s i=t=0}=w_{1}$ and recalling from $(2-i i)$ that $p F_{L}-w_{1}=$ $-\left(\mathrm{V}_{1}-\hat{\mathrm{U}}\right) / \mathrm{V}_{\mathrm{wl}}$ when unemployment exists, this implies

$$
\mathrm{df} /\left.\mathrm{dt}\right|_{\mathrm{Si}=t=0}=0
$$

(Proof that $t=s_{i}=0$ is a local maximum is presented in Appendix II.)

The preceding analysis permits us to conclude that free trade is a constrained Pareto optimum and hence that a small tariff at free trade cannot be Pareto improving. The intuition behind this result is as follows: In many models of incomplete markets (e.g. Stiglitz $(1982 a, \nu))$ the constrained suboptimality of the competitive equilibrium follows from the fact that competitive agents do not take into account the effect of their actions on the distribution of prices in the economy. In these environments prices play a dual role: they simultaneously allocate goods and distribute risk anong agents. Since the public good nature of prices is not taken into consideration by agents, the competitive market generally will not induce the optimal distribution of risk and a set of taxes may be Pareto improving.

This role for taxes is not available in the present context. Contracts have already been written in such a way as to provide the risk-averse agents with the optimal amount of insurance, i.e. the 
marginal utility of the wage is constant over states of nature, and the underlying distribution of prices is exogenous and hence cannot b changed by government policy. Thus the effect of the tariff is simply to move agents along the preestablished contract and to make availabl the associated tariff revenue.

Yet another insight into why a tariff is not Pareto improving may be derived from the theory of the second-best. The implicit contract, as its construction indicates, is optimal given the restrictions imposed, i.e., g ven the inability of entrepreneurs to insure unemployed workers. The production inefficiency inherent in the contract is an outcome of this restriction. The imposition of a tariff, however, does not create an additional market by which to bypass this restriction and it introduces an additional consumption inefficiency. Consequently, it is not to be expected that a tariff ma be Pareto improving in this economy.

\section{Concluding Remarks}

This paper examines the effect of a tariff in an economy with implicit contracts. The optimal contract is characterized and wages and employment are shown to differ in important ways from that predicted by standard models. Furthermore, it is shown that a tariff cannot constitute a Pareto improvement over free trade.

Several directions for further research are suggested by this approach. Most important is the role of an anticipated tariff or stat contingent trade policy on the part of the government, assuming that pre-commitment is feasible. This would, of course, affect the form of the contract itself. Another area to explore involves more 
sophisticated contract models in which the reasons for the second best nature of the contract is more firmly grounded in microeconomic theory, e.g. moral hazard stemming from asymmetric information. 


\section{APPENDIX I}

(2) and (3) determine $\mathrm{N}$ as a function of $\tilde{\mathrm{U}}$. Differentiation of (2-i) yields

$$
d w / d \tilde{U}=A \cdot[d N / d \tilde{U}-(d \lambda / d \tilde{U}) N / \lambda]
$$

where

$$
A=\left(U_{w W} \cdot \lambda\right)^{-1}<0
$$

Differentiating the Kuhn-Tucker conditions shows that, given full employment $\mathrm{de} / \mathrm{d} \tilde{\mathrm{U}}=0$ and that with unemployment $\mathrm{d} \gamma_{\mathrm{p}} / \mathrm{d} \tilde{\mathrm{U}}=0$. Hence, differentiation of $(2-i i)$ when unemployment exists yields

$$
\mathrm{de} / \mathrm{d} \tilde{\mathrm{U}}=\mathrm{BdN} / \mathrm{d} \tilde{\mathrm{U}}-\mathrm{Dd} \lambda / \mathrm{d} \overline{\mathrm{U}}
$$

where

$$
\mathrm{B}=\left[\mathrm{w}-\mathrm{p} \mathrm{F}_{\mathrm{L}}-\mathrm{p} \mathrm{F}_{\mathrm{LL}} \mathrm{eN}\right] /\left[\mathrm{pN}^{2} \mathrm{~F}_{\mathrm{LL}}\right]<0 \text { and } \mathrm{D}=(\mathrm{V}-\hat{\mathrm{U}}) /\left(\mathrm{pN}^{2} \mathrm{~F}_{\mathrm{LL}}\right)<0
$$

Differentiating (2-iii), substituting (A1) and (A3) where appropriate, and recalling the Kuhn-Tucker conditions obtains, after some manipulation,

$$
\mathrm{Ed} \lambda / \mathrm{d} \tilde{\mathrm{U}}+\mathrm{IdN} / \mathrm{d} \tilde{\mathrm{U}}=0
$$

where

$$
\begin{gathered}
E-\int e A N / \lambda-\int_{U} D\left[e_{L L} F_{L}+p F_{L}-w\right]<0 \text { and } \\
I=\int_{f}\left(e^{2} p F_{L L}\right)-\int_{U}\left[2 N e p F_{L L}+p F_{L}-w\right]\left[p F_{L}-w\right] /\left[p N^{2} F_{L L}\right]-\int e A
\end{gathered}
$$

where $\int_{u}$ indicates integration only over those states of nature in which unemployment exists and $\int_{f}$ only over those states of nature employment ( $\mathrm{dH}$ has been omitted throughout).

A similar procedure for the equation defining expected utility, 


$$
\begin{array}{r}
\int\{\mathrm{V}(w, p) e+\hat{U}(1-e)\} d H=\tilde{U}, \text { yields : } \\
J d \lambda / d \tilde{U}+K d N / d \tilde{U}=1
\end{array}
$$

where

$$
\begin{gathered}
J=-\int_{u}(V-\hat{U}) D+\int_{w} \text { eAN } / \lambda>0 \text { and } \mathrm{K}=\int_{\mathrm{u}}(\mathrm{V}-\hat{\mathrm{U}}) \mathrm{B}+\int_{\mathrm{w}} \text { eA }<0 \\
\text { Using (A5) to solve for } \mathrm{d} \lambda / \mathrm{d} \tilde{\mathrm{U}} \text { and substituting into (A7) yields: } \\
\mathrm{dN} / \mathrm{d} \tilde{\mathrm{U}}\{\mathrm{E} \cdot \mathrm{K}-\mathrm{J} \cdot \mathrm{I}\}=\mathrm{E}
\end{gathered}
$$

so that sign $d N / d \widetilde{U}=-\operatorname{sign}(E \cdot K-J \cdot I)$. Manipulating (A9) yields sign $\{\mathrm{E} \cdot \mathrm{K}-\mathrm{J} \cdot \mathrm{I}\}>0$ and hence $\mathrm{dN} / \mathrm{d} \tilde{\mathrm{U}}<0$. 
APPENDIX II

Proof that the free trade equilibrium is a local maximum for (23) follows.

(i). $\partial^{2} f /\left.\partial t^{2}\right|_{t=s=0}=\operatorname{Vyl}\left(p^{\star 2}\left[(\partial \mathrm{hl} / \mathrm{dp}) \cdot \mathrm{Ll}+(\partial \mathrm{h} 2 / \mathrm{dp}) \cdot \mathrm{N}_{2}\right]+\mathrm{pF}_{\mathrm{LL}}\left(\mathrm{dL} \mathrm{L}_{\mathrm{l}} / \mathrm{dt}\right)^{2}\right.$. $\left.\mathrm{p}^{\star 2}\left[\left(\partial \mathrm{C}_{1} / \partial \mathrm{y}_{1}\right) \cdot \Phi_{1} \mathrm{C}_{1} \mathrm{~L}_{1} / \mathrm{R}_{1}+\left(\mathrm{C}_{2} / \partial \mathrm{y}_{2}\right) \cdot \Phi_{2} \mathrm{C}_{2} \mathrm{~L}_{2} / \mathrm{R}_{2}\right]\right) \mathrm{N}_{2}<0$

where $\partial h_{i} / \partial p$ is the substitution term in the slutsky equation.

(ii). $\partial^{2} E / \partial t^{2} \cdot \partial^{2} f / \partial s_{1}^{2}-\left.\left(\partial^{2} E / \partial t \partial s_{1}\right)^{2}\right|_{t=s=0}=$

$\mathrm{V}_{\mathrm{ylyl}} \mathrm{V}_{\mathrm{yl}} / \mathrm{L}_{1} \cdot\left(\mathrm{p}^{* 2}\left[\left(\partial \mathrm{h}_{1} / \mathrm{dp}\right) \cdot \mathrm{L}_{\mathrm{l}}+\left(\partial \mathrm{h}_{2} / \mathrm{dp}\right) \cdot \mathrm{N}_{2}\right]+\mathrm{pF}_{\mathrm{LL}}\left(\mathrm{dL} \mathrm{L}_{1} / \mathrm{dt}\right)^{2}-\right.$ $\left.\left.\mathrm{P}^{\star 2}\left[\partial \mathrm{C}_{2} / \partial \mathrm{y}_{2}\right) \cdot \Phi_{2} \mathrm{C}_{2} \mathrm{~L}_{2} / \mathrm{R}_{2}\right]\right)>0$.

(iii). The third principal minor yields:

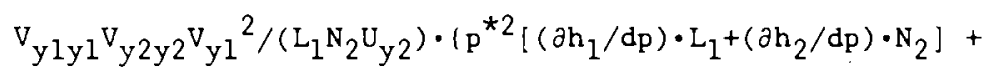
$\left.\mathrm{pF}_{\mathrm{LL}}\left(\mathrm{dL} \mathrm{L}_{\mathrm{l}} / \mathrm{dt}\right)^{2}\right)<0$.

(iv). The fourth principal minor equals zero. 


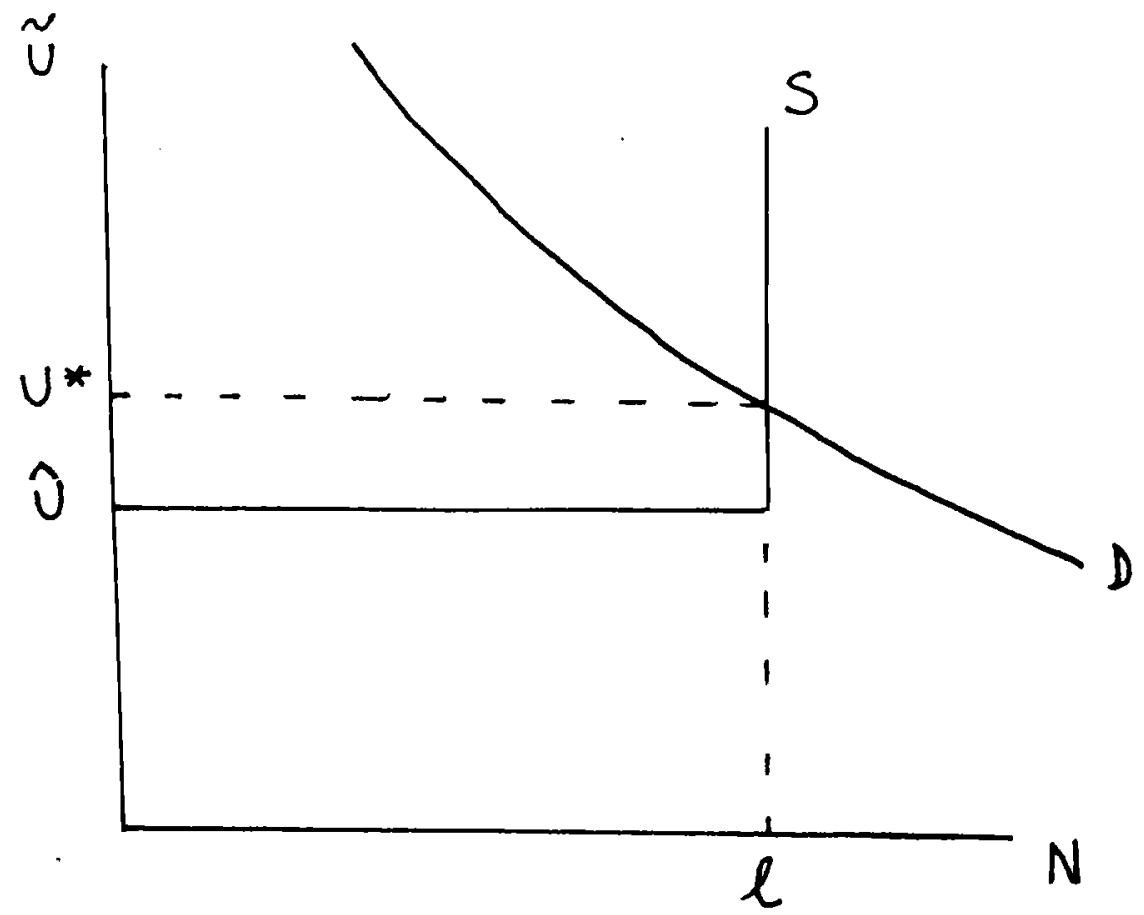

FIGURE 1

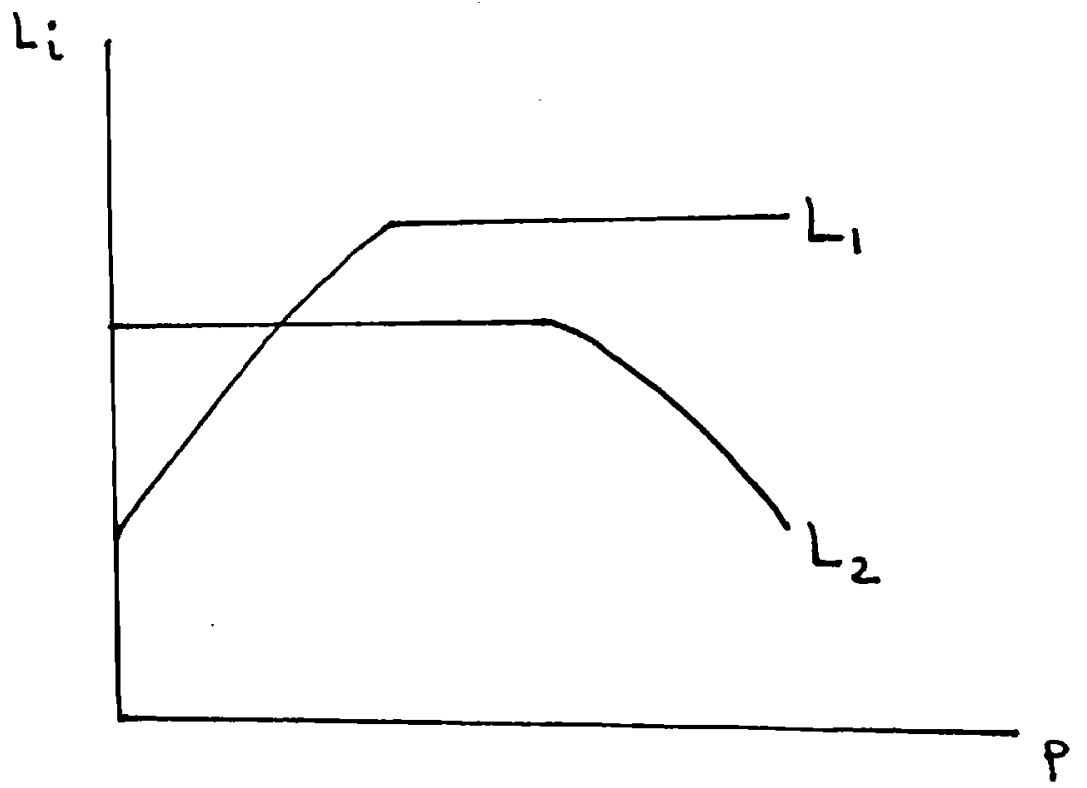

FIGURE 2 


\section{BIBLIOGRAPHY}

Akerlof,G. and Miyazaki,H., "The implicit contract theory of unemployment meets the wage bill argument," Review of Economic Studies, $1980,47,321-38$.

Azariadis, Costas, "Implicit contracts and underemployment equilibria," Journal of Political Economy, Dec. 1975, 83, 1183-1202.

" ". "Employment with Asymmetric Information," Quarterly Journal of Economics, 1983, 98, 157-73.

Baily, Martin H., "Wages and employment under uncertain demand," Review of Economic Studies, 1974, 41, 37-50.

Brecher, Richard, "Minimum wage rates and the pure theory of international trade," Quarterly Journal of Economics, 1974, 88, 98116.

Dixit, Avinash, "Trade and insurance with moral hazard," mimeo, Princeton University, October 1986.

Eaton, Jonathan and Gene M. Grossman, "Tariffs as insurance: optimal commercial policy when domestic markets are incomplete," Canadian Journal of Economics, May 1985, 18, 258-272.

Ethier, Wilfred, "Dumping," Journal of Political Economy, 1982, 90. $487-506$.

" ". "International trade and labor migration," American Economic Review, Sept. 1985, 75, 691-707.

Gordon, Donald F., "A neoclassical theory of Keynesian unemployment," Economic Inquiry, 1974, 12, 431-59.

Grossman, Sanford and Oliver Hart, "Implicit contracts under asymmetrical information," Quarterly Journal of Economics, 1983, 71, $123-57$. 
Hart, Oliver and Bengt Holmstrom, "The Theory of Contracts," in Advances in Economic Theory, ed. Truman Bewley, Cambridge University Press, forthcoming.

Helpman, Elhanan and Assaf Razin, "Uncertainty and international trade in the presence of stock markets," Review of Economic Studies, $1978,45,239-50$.

Horn, Henrik and Lars E.O. Svensson, "Trade unions and optimal labor contracts, " Economic Journal, June 1986, 96, 323-41.

Johnson, Harry G., "Optimal trade intervention in the presence of domestic distortions," in Trade, Growth, and the Balance of Payments (ed. R. Caves, H. Johnson, and P. Kenen) Chicago: Rand Mcnally and Co., 1965 .

Jones, Ronald, "A three factor model in theory, trade and history," in J.N. Bhagwati et al., eds., Trade, Balance of Payments and Growth, Amsterdam: North Holland, 1971.

Lapan, Harvey, International trade, factor market distortions and the optimal subsidy," American Economic Review, 1976, 66, 335-46.

Matusz, Steven, "The Heckscher-Ohlin-Samuelson model with implicit contracts," Quarterly Journal of Economics. Nov. 1985, 1313-1329.

" ", "Implicit Contracts, unemployment and international trade, Quarterly Journal of Economics, June 1986, 96, 307-322.

Neary, Peter J., "International capital mobility, wage stickiness, and the case of adjustment assistance," in Import Competition and

Response, ed. J.N. Bhagwati, Chicago: The University of Chicago Press. Newbery, D.M.G. and Joseph E. Stiglitz, "Pareto Inferior Trade," Review of Economic Studies, 1984, 51, 1-13.

Rosen, Sherwin, "Implicit contracts," Journal of Economic Literature, 
Sept. 1985, 1144-1175. 